\title{
Quasi-two-day wave in the lower atmosphere over Hyderabad during summer of 2009
}

\author{
G. Dutta ${ }^{1}$, S. Mohammad ${ }^{1}$, M. Satyakumar ${ }^{2}$, Y. K. Reddy $^{2}$, P. Vinay Kumar ${ }^{1}$, P. V. Rao ${ }^{3}$, and M. C. Ajay Kumar ${ }^{4}$ \\ ${ }^{1}$ Vignana Bharathi Institute of Technology, Aushapur, Hyderabad, India \\ ${ }^{2}$ India Meteorological Department, Begumpet, Hyderabad, India \\ ${ }^{3}$ Vasavi College of Engineering, Ibrahimbagh, Hyderabad, India \\ ${ }^{4}$ Vanjari Seethaiah Memorial College of Engg., Patancheru, Hyderabad, India
}

Correspondence to: G. Dutta (gopadutta@yahoo.com)

Received: 11 January 2011 - Revised: 21 September 2011 - Accepted: 4 October 2011 - Published: 6 January 2012

\begin{abstract}
The characteristics of the quasi-2-day wave (QTDW) in the lower atmosphere $(1-50 \mathrm{~km})$ has been investigated using wind and temperature data obtained from India Meteorological Department (IMD), Hyderabad (17.4 $\mathrm{N}$, $78.5^{\circ} \mathrm{E}$ ) and ECMWF Re-Analysis (ERA-interim) data for $\left(18^{\circ} \mathrm{N}, 78^{\circ} \mathrm{E}\right)$ which is the nearest grid to the location of observation. Wind and temperature data of IMD between 15 May and 24 September 2009 in the altitude range of $1-25 \mathrm{~km}$ have been used for the present study. Simultaneous ERA data of wind and temperature for the same period between the pressure levels of 1-1000 $\mathrm{mb}$ have been analyzed for 2day wave activity. Appreciable amplitudes of the wave $(\sim 2-$ $3 \mathrm{~m} \mathrm{~s}^{-1}$ ) could be observed in both IMD and ERA datasets of winds. The thermal amplitude maximum is $\sim 1.5 \mathrm{~K}$ in the lower stratosphere (IMD). Amplitudes obtained from ERA data are found to be less than those obtained from IMD measurements. Maximum wind amplitudes $\left(1.5-2 \mathrm{~m} \mathrm{~s}^{-1}\right)$ are observed in the UTLS region and in the upper stratosphere between $35-45 \mathrm{~km}$. Peak value of temperature oscillation in the upper stratosphere is $\sim 1 \mathrm{~K}$. Wavelet analyses show systematic bursts of QTDW during the summer solstice with a gap of $\sim 5-8$ days. The striking similarity between the results of IMD and ERA data can be appreciated. The squaredcoherence values between the two datasets in terms of crossspectral amplitudes are found to be highly significant for 2day wave in the lower atmosphere.
\end{abstract}

Keywords. Ionosphere (Wave propagation) - Meteorology and atmospheric dynamics (General circulation; Middle atmosphere dynamics)

\section{Introduction}

The quasi-2-day wave is a common feature of the middle and upper atmosphere in both the hemispheres. This westward propagating global oscillation becomes predominant near solstices and has been detected in wind and temperature measurements (Wu et al., 1996; Lieberman, 1999; Jacobi et al., 1997). The perturbation is, in general, stronger in meridional wind and maximizes at low latitudes (Norton and Thuburn, 1996). Hemispheric differences have been observed in the characteristics of 2-day wave with much larger wave amplitudes in Southern Hemisphere. The meridional fluctuations are found to be in phase between the hemispheres whereas zonal fluctuations are nearly out of phase. The period of the wave is found to be $\sim 48-49 \mathrm{~h}$ with zonal wave number 3 in the Southern Hemisphere but it varies between 44 to $52 \mathrm{~h}$ with zonal wave number 3 and 4 in the Northern Hemisphere at mesospheric heights (Randel, 1994; Meek et al., 1996). A wave number 2 disturbance with a near 2-day period has also been reported (Wu et al., 2008; Palo et al., 2007). Recently Limpasuvan and Wu (2009) observed an anomalous behavior of QTDW with a large range of frequency and wave number. The 2-day wave is also observed to play a vital role in mesospheric dynamics through non-linear interaction with the migrating diurnal tide (McCormack et al., 2010; Palo et al., 2007; Pancheva et al., 2004). The wave is also reported to play a significant role in the horizontal distribution of minor gas constituents at mesopause level (Kulikov, 2007).

The excitation of QTDW in the middle atmosphere can be explained by two mechanisms. Salby (1981) gave the interpretation of the 2-day wave as a manifestation of the $(3,0)$ normal Rossby gravity wave mode. The enhancement of this normal mode is observed in the summer hemisphere which 

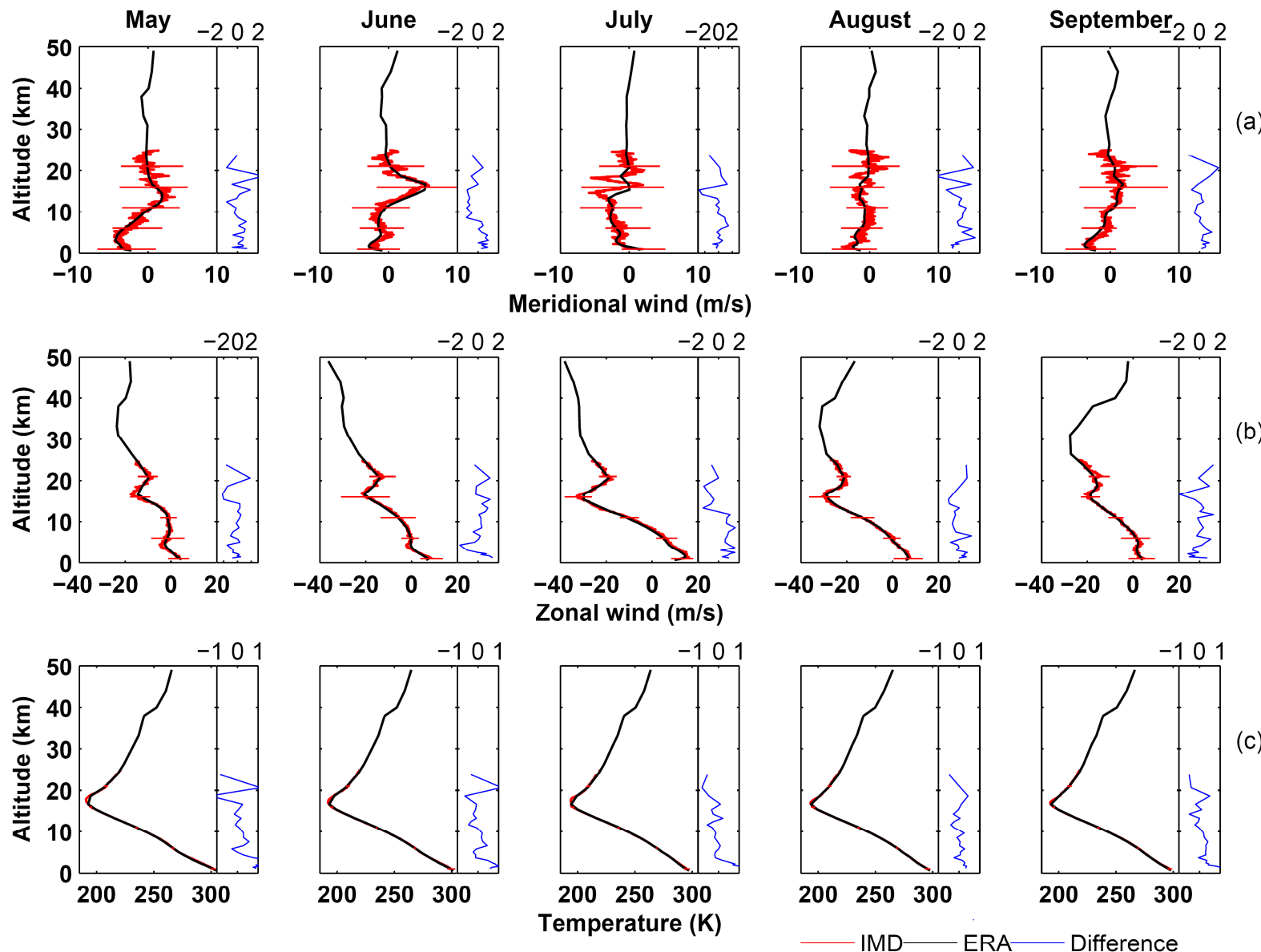

(a)

(b)

(c)

Fig. 1. Mean monthly profiles of meridional (a), zonal (b) winds and temperature (c) of IMD (red) and ERA (black) with standard deviations at a few heights on measured profiles. The differences between IMD and ERA profiles (blue) are plotted in the right panels of corresponding months.

is consistent with the theory. The seasonality of QTDW has given rise to another interpretation of its source as the baroclinic and barotropic instability of the summer easterly jet (Salby and Callaghan, 2001; Mayr et al., 2001). The two day wave is observed to be present throughout the year with strongest bursts during summer (Wu et al., 1993; Pancheva et al., 2004). The temperature perturbation is higher in the summer hemisphere and leaks into the winter hemisphere across the equator. Analyzing Microwave Limb Sounder (MLS) temperatures in a broad height range of $22-73 \mathrm{~km}$ $(46-0.46 \mathrm{mb}) \mathrm{Wu}$ et al. (1996) suggested the possible connection between the summer 2-day wave and the winter planetary wave activity. From the amplitude and phase structures of the wave, they suggested that the wave could transport momentum and energy from the winter at low heights into the summer at higher altitudes and that the 2-day wave is a combination of normal and unstable mode. Randel (1994) studied five years of National Meteorological Center (NMC) operational stratospheric analyses and reported similar observations.
Extensive investigations have been carried out to study 2day wave activity at mesospheric heights. Its characteristics in the lower atmosphere (troposphere and stratosphere) are still almost unexplored. Orlanski (1976) investigated the dynamics due to trapeze instability and presented the evidence of near-2-day wave oscillations in atmospheric parameters particularly in the lower tropospheric zonal and meridional winds. Subsequently Krishnamurthy and Bhalme (1976) carried out spectral analyses of some meteorological parameters and clearly demonstrated quasi-2-day oscillations in some of the parameters. The present paper reports measurements of QTDW in the troposphere and lower stratosphere (1-25 km) over Hyderabad $\left(17.4^{\circ} \mathrm{N}, 78.5^{\circ} \mathrm{E}\right)$, a tropical Indian station using GPS-radiosonde data. Analysis of 2-day wave has also been carried out using ECMWF reanalysis data (ERAinterim) over the same station between $(1-50) \mathrm{km}$ and compared with the measured values. 

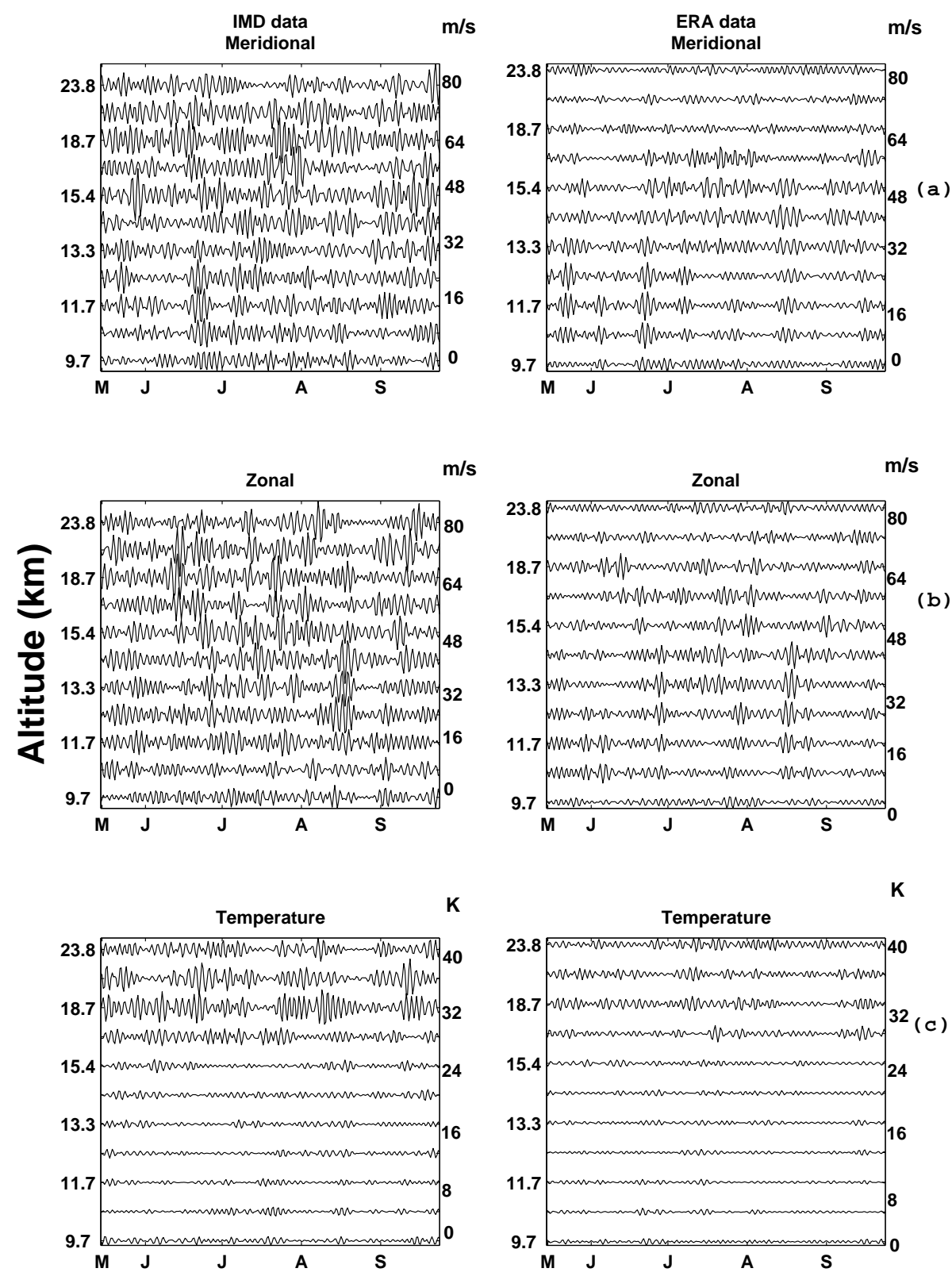

\section{Month}

Fig. 2. Time series of fluctuations of meridional (a), zonal (b) winds and temperature (c) of IMD and ERA datasets with appropriate shifts. Winds and temperature fluctuations are shifted vertically by $8 \mathrm{~m} \mathrm{~s}^{-1}$ and $4 \mathrm{~K}$.

\section{Data and analysis}

India Meteorological Department (IMD) carries out routine GPS-radiosonde flights twice a day at 00:00 GMT (05:30 LT) and 12:00 GMT (17:30 LT) from Hyderabad. The radiosondes are manufactured by MODEM company of France. It has on-board GPS receiver, sensors for temperature and humidity and a $402 \mathrm{MHz}$ transmitter. The ground equipment receives the data and feeds to the processing com- puter. The software 1R2K2 developed by MODEM acquires the data and extracts the meteorological parameters. It also receives Base GPS data and uses for differential computation which improves the accuracy of wind data. The accuracies of wind and temperature are $0.15 \mathrm{~m} \mathrm{~s}^{-1}$ and $\pm 0.5^{\circ} \mathrm{C}$ respectively (Ref: http://www.meteomodem.com/ doc/en/Broch-GPSonde\%20M2K2DC-US.pdf).

The data collected between 15 May and 24 September 2009 have been used for the present study. Wind and 

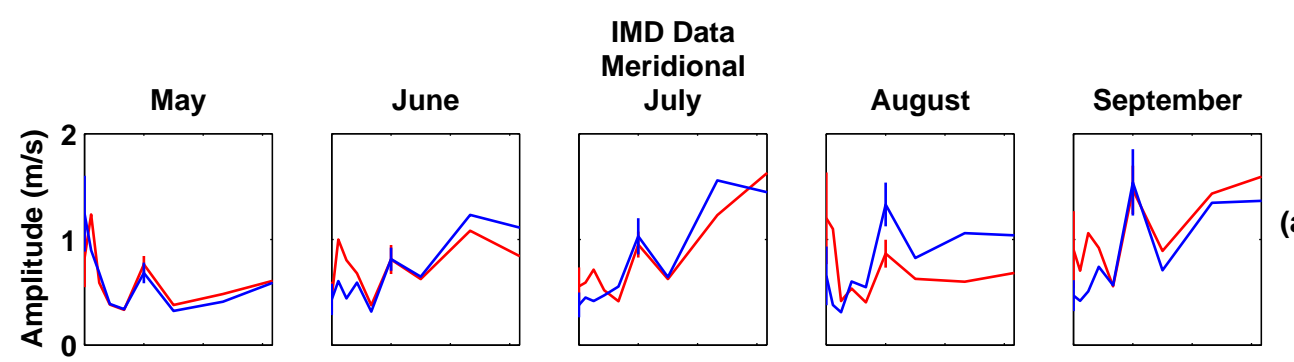

(a)
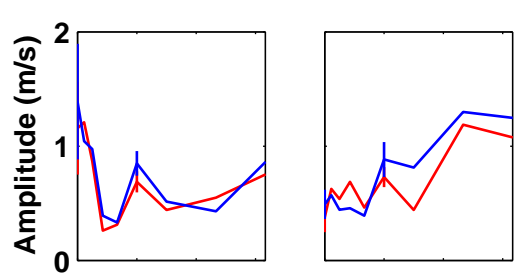

\section{Zonal}
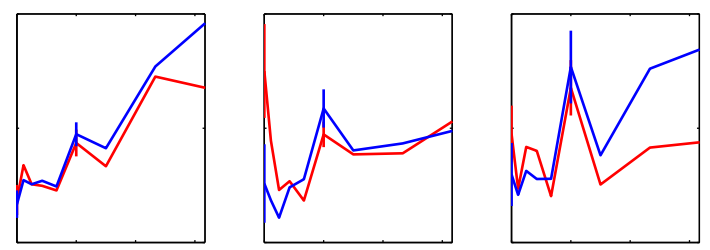

(b)
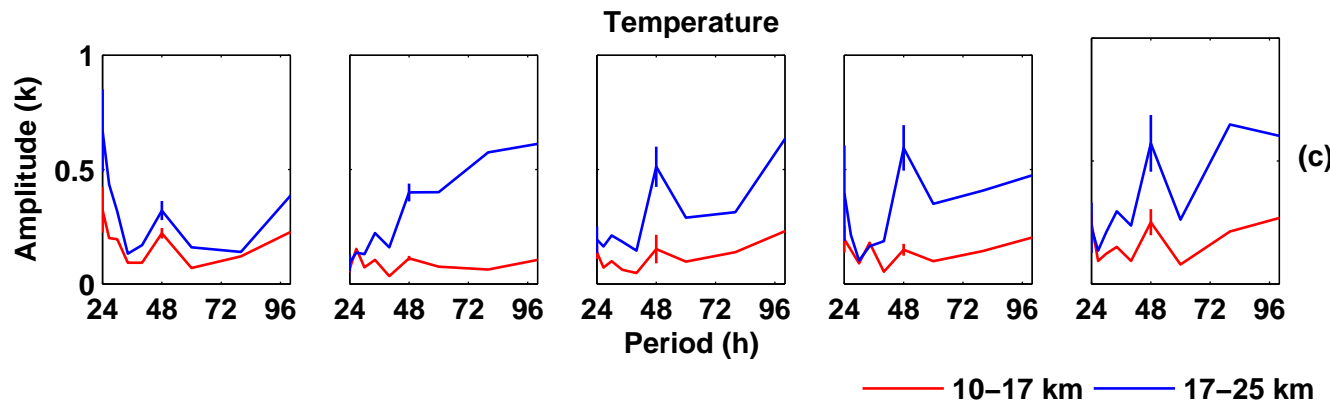

Fig. 3. Monthly FFT spectra of meridional (a), zonal (b) wind and temperature (c) fluctuations of IMD datasets for different height blocks. Vertical bars showing $95 \%$ confidence level are plotted on 2-day wave peaks.

temperature data have been interpolated for every $50 \mathrm{~m}$ to obtain consistent datasets. There were no flights for a few days and some flights could not reach upto $25 \mathrm{~km}$ though most of the flights could make it. The data were spline interpolated time-wise to fill these scattered gaps. Outliers were removed by discarding values exceeding 2 times the standard deviation from the monthly mean values. Data gaps, if any, with respect to height were filled up by linear interpolation. The quality of the data was quite good and such outliers were found to be rare. The ECMWF Re-Analysis (ERA-interim) data of wind and temperature for $18^{\circ} \mathrm{N}, 78^{\circ} \mathrm{E}$ which is closest to the location of Hyderabad have been downloaded from the site http://data-portal.ecmwf.int/data/ $\mathrm{d} /$ interim-daily/leveltype $=\mathrm{pl} /$ for the same period of time (15 May 2009 to 24 September 2009) between the pressure levels 1 to $1000 \mathrm{hPa}$. The wind and temperature profiles obtained from IMD and ERA datasets were then averaged for each month and their vertical structures are displayed in Fig. 1a, b, c, left part of panels. Standard deviations of IMD data have been plotted at an interval of $5 \mathrm{~km}$. The differences between IMD and ERA datasets have been displayed in the right panels of corresponding months. The observed discrepancies are $\pm 2 \mathrm{~m} \mathrm{~s}^{-1}$ for winds and $\pm 1 \mathrm{~K}$ for temperature which are quite negligible. Strong easterlies of the order of $-34 \mathrm{~m} \mathrm{~s}^{-1}$ and $-29 \mathrm{~m} \mathrm{~s}^{-1}$ can be seen in the months of July and August respectively at $\sim 16$ to $16.5 \mathrm{~km}$.

The time-wise continuous datasets of winds and temperature were detrended and FFT (Fast Fourier Transform) analyses were carried out which showed the presence of waves with periods close to $48 \mathrm{~h}$ (figure not shown) in spite of the difficulty to identify it in the presence of strong planetary waves with longer periods (Wu et al., 1996). The fluctuations corresponding to the 2-day wave were then reconstructed using the FFT amplitudes and phases of waves with periods between 42 and $70 \mathrm{~h}$ (inertia gravity wave period over Hyderabad is $\sim 40 \mathrm{~h}$ ) and integrating them for each height. The time series of these fluctuating wind and temperature components are illustrated in Fig. 2 for a few heights of IMD and ERA datasets. Larger amplitudes may be noticed between $12-20 \mathrm{~km}$ for winds and between $18-23 \mathrm{~km}$ for temperature. The transient nature of the oscillation can also be noticed. ERA data of winds show lesser amplitudes of oscillations between $25-35 \mathrm{~km}$ which again picks up in the upper stratosphere. Temperature oscillations in ERA data are found to 


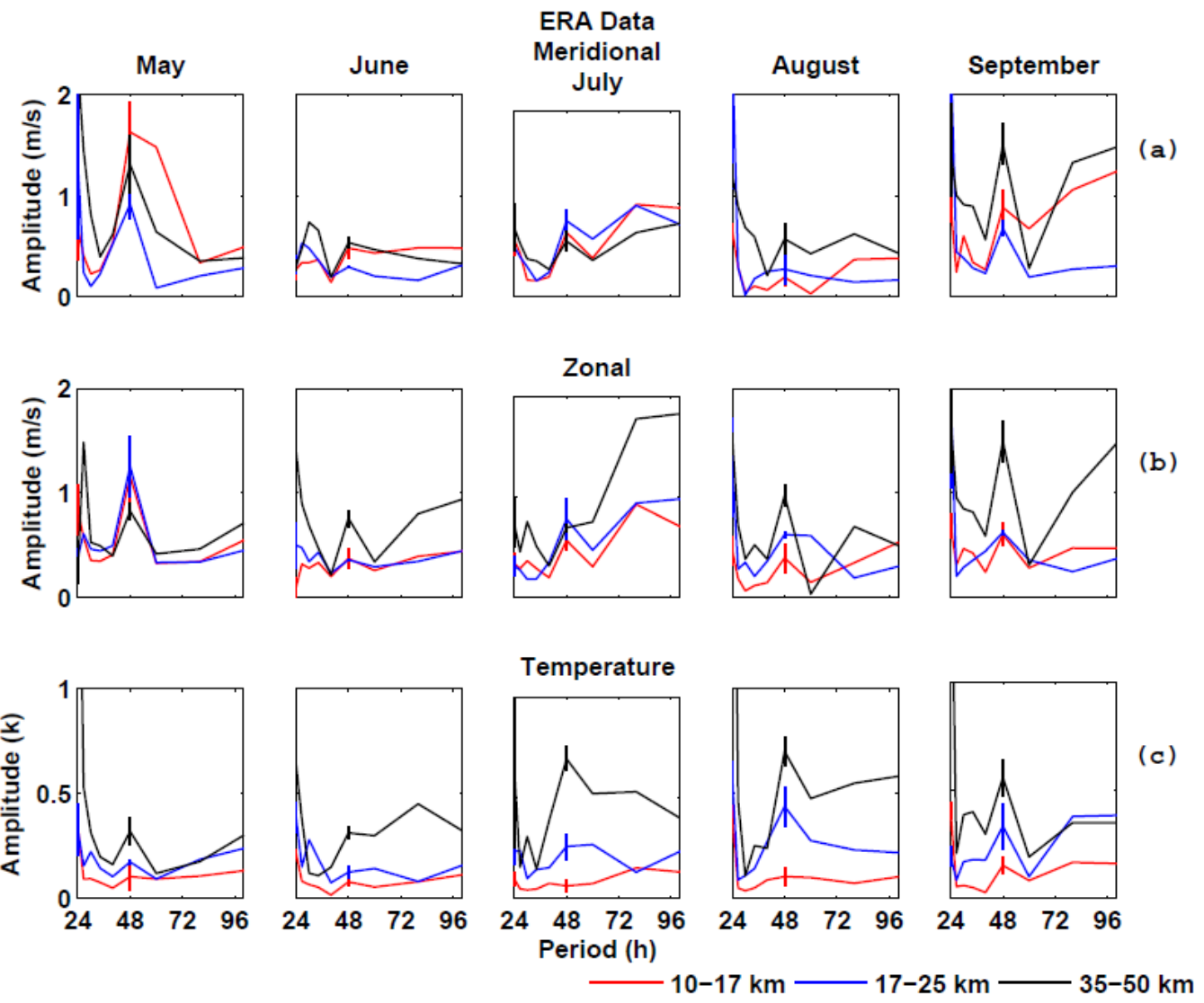

Fig. 4. Same as Fig. 3 but for ERA datasets.

be appreciable almost throughout the stratosphere with maximum values between $40-50 \mathrm{~km}$. Simultaneous altitudes are shown in the figure for comparison with IMD data.

\section{Results and discussion}

\subsection{Spectral analyses}

\subsubsection{FFT spectra}

Monthly datasets of winds and temperature were subdivided into smaller 10 day segments to avoid long period ( $>5$ day) oscillations and detrended to obtain corresponding fluctuations. Interpolated data were carefully avoided in choosing the segments. The fluctuating components of different segments were overlapped by $\sim 50 \%$ and subjected to FFT analyses which reduced the variance associated with each spectral estimate (Press et al., 1992). The spectra obtained were then averaged to get one spectrum for each altitude. The 2-day wave was quite prominent at most of the heights. FFT spectra were then averaged over altitudes between 10$17 \mathrm{~km}, 17-25 \mathrm{~km}$ and $35-50 \mathrm{~km}$ (ERA) where 2-day wave peaks were seen clearly despite the presence of tidal and 45 day oscillations, thereby further enhancing their spectral reliabilities. Spectra of different months for different altitude zones are depicted in Fig. 3 (IMD) and Fig. 4 (ERA). Confidence limits at $95 \%$ level are shown with vertical bars on 2-day wave peaks. Peaks with similar periods are observed in all the regions. Wind spectra are found to have stronger oscillations in the upper troposphere whereas temperature oscillations are found to dominate the lower stratosphere as mentioned in Sect. 2. The striking similarities of the periods observed in IMD and ERA datasets make us confident about the results obtained in the present analyses. The averaged amplitudes of the measured (IMD) wind spectra are found to be little larger than those obtained from ERA data for the same altitude regions. The meridional amplitudes between $35-50 \mathrm{~km}$ (ERA) are somewhat higher than other regions for the months of August and September where as the amplitudes in the upper troposphere dominate the months of May and June. The spectra of temperature oscillations show very clear trends. Oscillations in the lower stratosphere are found to be dominant in the IMD datasets (Fig. 3c) compared to upper troposphere. Spectra of the ERA data (Fig. 4c) show strongest oscillations in the upper stratosphere followed by lower stratosphere and upper troposphere. Randel (1994) reported weak temperature wave amplitudes at $10 \mathrm{mb}$, but observed strong statistical coherence between $1 \mathrm{mb}$ and $10 \mathrm{mb}$ $(\sim 31 \mathrm{~km}$ and $\sim 50 \mathrm{~km})$ levels. 

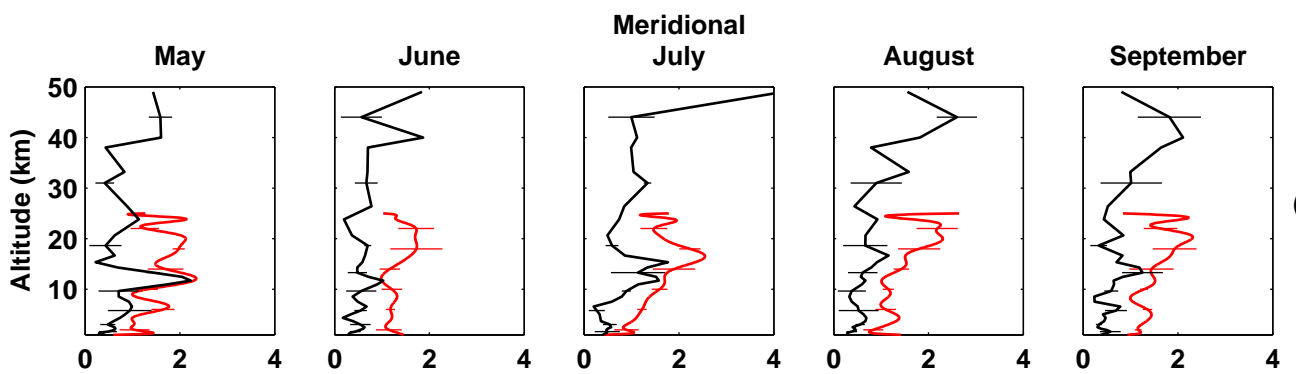

(a)
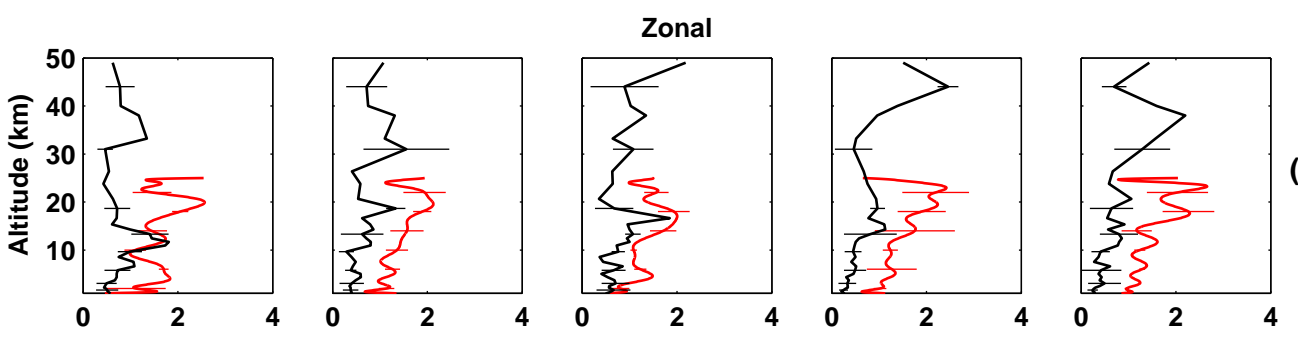

(b)
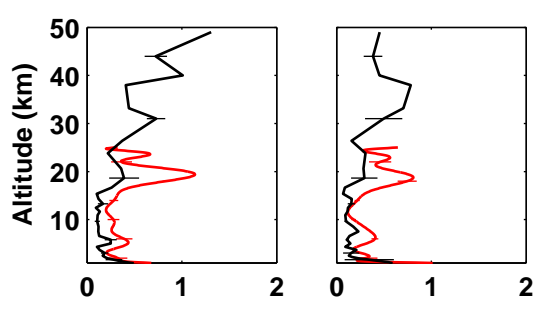

Temperature
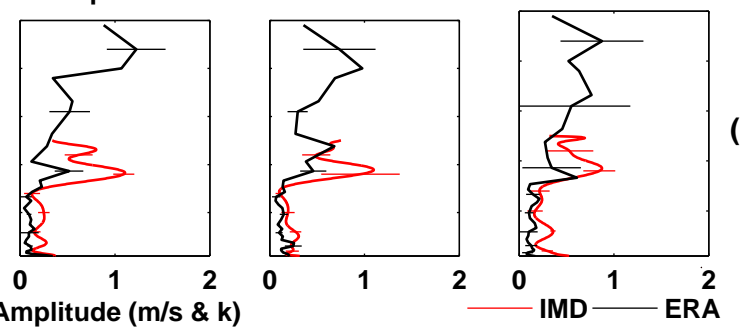

Fig. 5. Height profiles of meridional (a), zonal (b) and temperature (c) amplitudes of quasi-2-day oscillations with standard deviations at a few heights with corresponding colors.

Comparisons of mean amplitude height profiles of 2-day wave obtained from IMD and ERA data sets of winds and temperature are illustrated in Fig. 5a, b, c with standard deviations at a few heights. Higher order polynomials were fitted to give smooth looks to the profiles. The measured amplitudes are found to be larger than the model amplitudes. Higher amplitudes of the wave can be observed in the upper stratosphere mostly between $35-50 \mathrm{~km}$ with another maximum near the tropopause in ERA data. The vertical structure of QTDW possibly indicates different sources of the wave in the two regions. The upward heat flux in the planetary boundary layer (PBL) and the low level jet in the troposphere might generate the wave in the lower atmosphere. The strong easterly jet below the tropopause during the summer monsoon season could be another source of 2-day wave activity. Maximum amplitudes observed in ERA data are $\sim 1.5-$ $2 \mathrm{~m} \mathrm{~s}^{-1}$ for winds and $\sim 0.8-1 \mathrm{~K}$ for temperature oscillations. Larger amplitudes are seen in the high resolution $(50 \mathrm{~m})$ measurements of IMD which are $\sim 3 \mathrm{~m} \mathrm{~s}^{-1}$ for winds and $1.5 \mathrm{~K}$ for temperature. The present study shows comparable amplitudes of QTDW for both zonal and meridional winds. Similar observations were reported by Jacobi et al. (1997) for a mid-latitude station at mesospheric heights.
Observational studies of two-day wave in the lower atmosphere to compare with the present work are very rare. But planetary waves observed in the mesosphere and lower thermosphere are reported to be related to planetary waves observed in the stratosphere (Vincent, 1990). The quasi2-day wave has also been identified in the spectra of surface pressure and other meteorological parameters (Hamilton and Garcia, 1986; Orlanski, 1976; Ngara and Asnani, 1978; Krishnamurthy and Bhalme, 1976). Using five years of National Meteorological Center (NMC) operational stratospheric analyses temperature data Randel (1994) reported clear maxima of temperature waves in the upper stratosphere for zonal wave numbers $3-4$ with periods $2-2.5$ days i.e. 48-60 h. Based on numerical calculations Merzlyakov and Jacobi (2004) observed a secondary 2-day wave with a period of 56-60 h due to the interaction between 10-14 day planetary waves with 2-day wave of zonal wave number 4 .

The present study has been carried out during MaySeptember, the period of Indian Summer Monsoon (ISM) which is a unique phenomenon in global tropics. The monsoon activity however does not remain uniform over this period and there are active and break spells. Using daily averaged National Centers for Environmental Prediction/ 


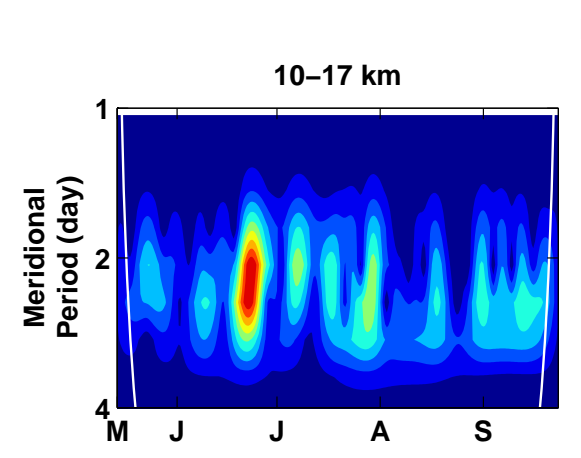

IMD
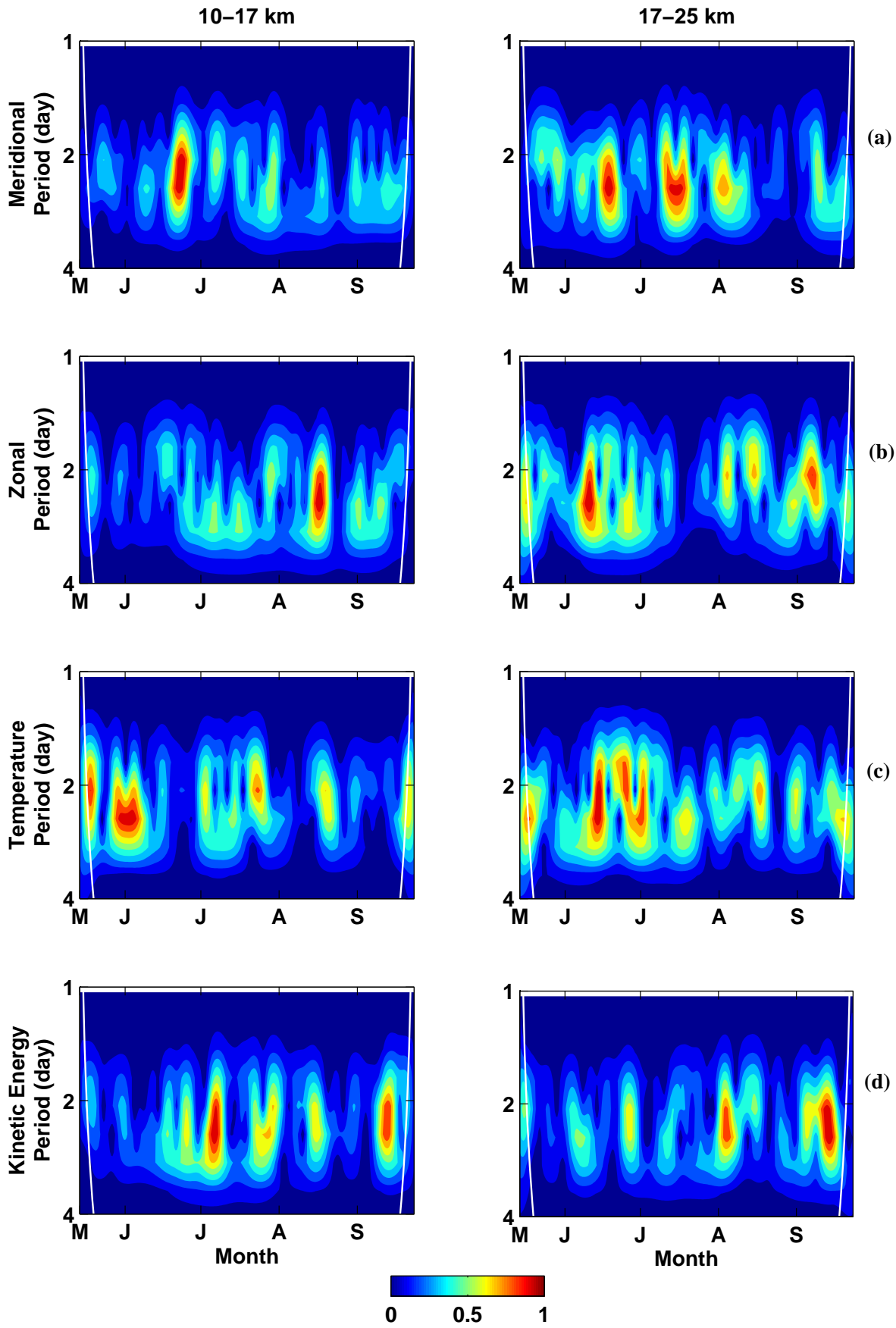

Fig. 6. Wavelet transform spectra of meridional (a), zonal (b) winds, temperature (c) and kinetic energy (d) for 10-17 km and 17-25 km altitude blocks (IMD data). Lower portions of cones of influence have been truncated for clarity.

National Centre for Atmospheric Research (NCEP/NCAR) re-analyses data of surface winds over the Indian monsoon region, Goswami et al. (1998) reported two dominant modes of Intra-seasonal oscillations (ISOs) with periods between 30-60 days and 10-20 days propagating in eastward and westward directions respectively. They also observed strong association between ISOs and synoptic scale (2-10 days) variations resulting in modulation and organization of the synoptic activity. The $30-60$ day mode is found to be closely related to active/break spells of ISM and was instrumental in enhancing/inhibiting synoptic activity. 

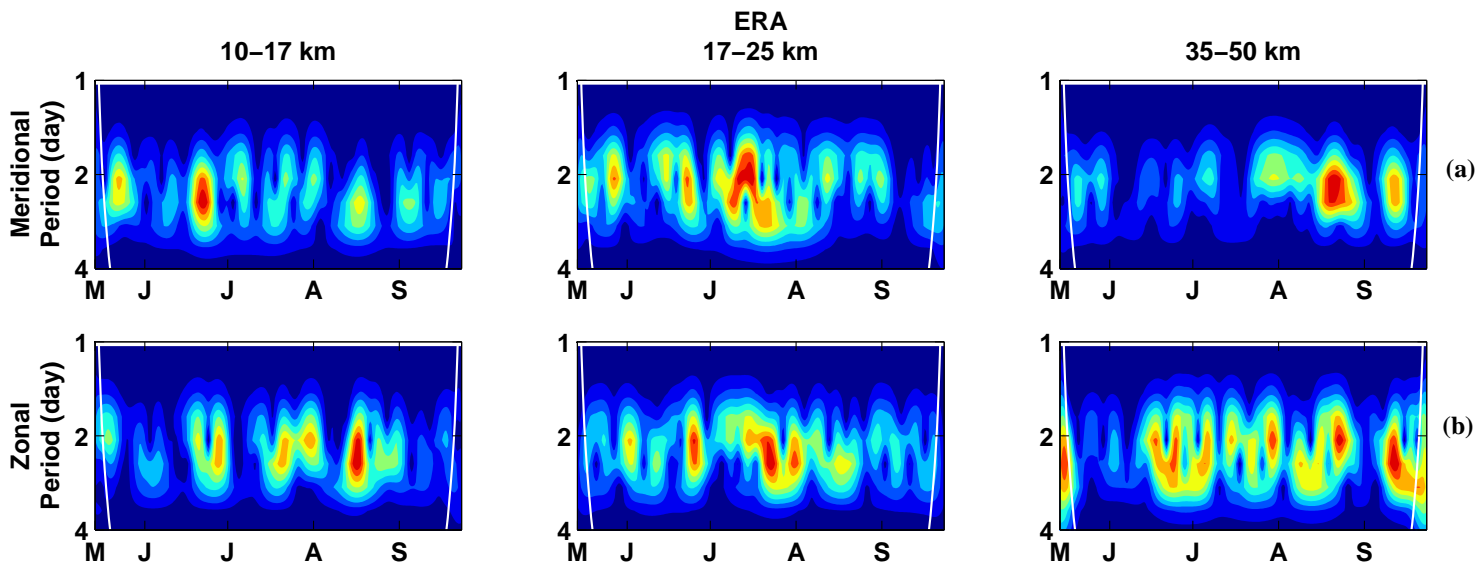

(b)
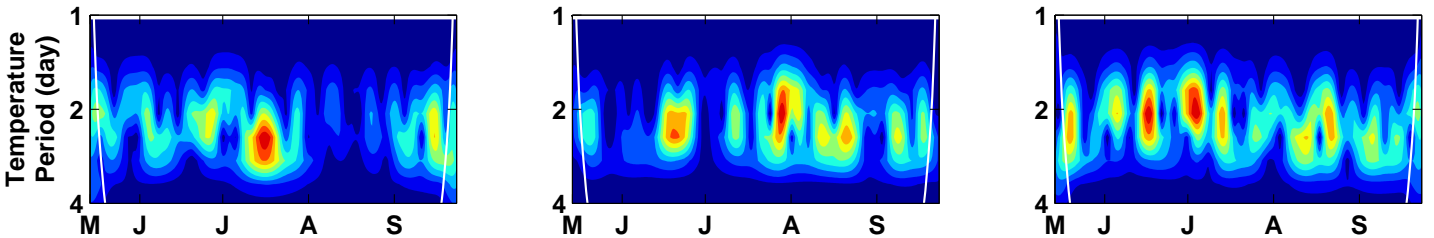

(c)
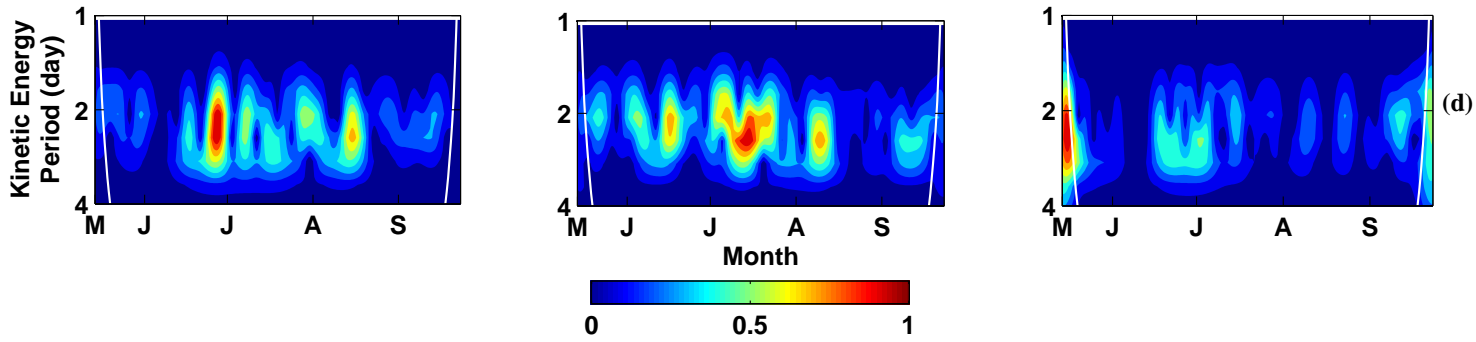

Fig. 7. Same as Fig. 6 but for 10-17 km, 17-25 km and 35-50 km (ERA data).

The phase profiles of 2-day wave do not show any clear propagation trend (figure not shown) indicating barotropic nature which is more typical of a normal mode disturbance.

\subsubsection{Wavelet spectra}

The quasi-2-day wave is present almost through out the year particularly near the equator where the signal is strong. It becomes more prominent around solstices. The temporal variation of the wave activity in the lower atmosphere around the summer solstice has been investigated by wavelet analyses of IMD and ERA datasets using Morlet wavelet. The wavelet transform is best suited to look into the temporal localization of the wave activity. Time series of kinetic energies have been calculated for each height using the standard formula $K . E .=\frac{1}{2}\left(u^{\prime 2}+v^{\prime 2}\right)$ where $u^{\prime}$ and $v^{\prime}$ are the zonal and meridional wind perturbations. Perturbations of wind velocities, temperatures and kinetic energies between 15 May and 24 September are then subjected to FFT analyses and the fluctuations between 42 and $70 \mathrm{~h}$ are reconstructed following the procedure mentioned in Sect. 2. Wavelet analyses were then carried out on the time-series of these constructed fluctuating components. The results of mean tropospheric (10-
$17 \mathrm{~km}$ ) and lower stratospheric (17-25 km) spectra (IMD) are normalized to a peak value of +1 at the highest amplitude and are depicted in Fig. 6a, b, c, d. The normalized spectra of ERA datasets for the same parameters for three height blocks $(10-17 \mathrm{~km}, 17-25 \mathrm{~km}$ and $35-50 \mathrm{~km})$ are shown in Fig. 7a, b, c, d. Lower portions of the cones of influence which are outside the wave bursts have been truncated to show the contours clearly. The major portions of the wave activity are found to be within the cones and are not affected by edge effects. Systematic bursts of 2-day wave activity can be visualized intermittently during the summer solstice. The relative amplitudes and patterns are almost similar for winds, temperature and also mean kinetic energy. Spectacular similarity between the IMD and ERA spectra can also be noticed. Sporadic bursts of activity are evident at an interval of $\sim 5$ 8 days.

\subsection{Cross-spectra and coherence}

The significance of the 2-day wave has been tested by computing the cross-spectra and coherence between IMD and ERA datasets of winds and temperature for different months. Mean cross-spectra were calculated in a similar manner as 

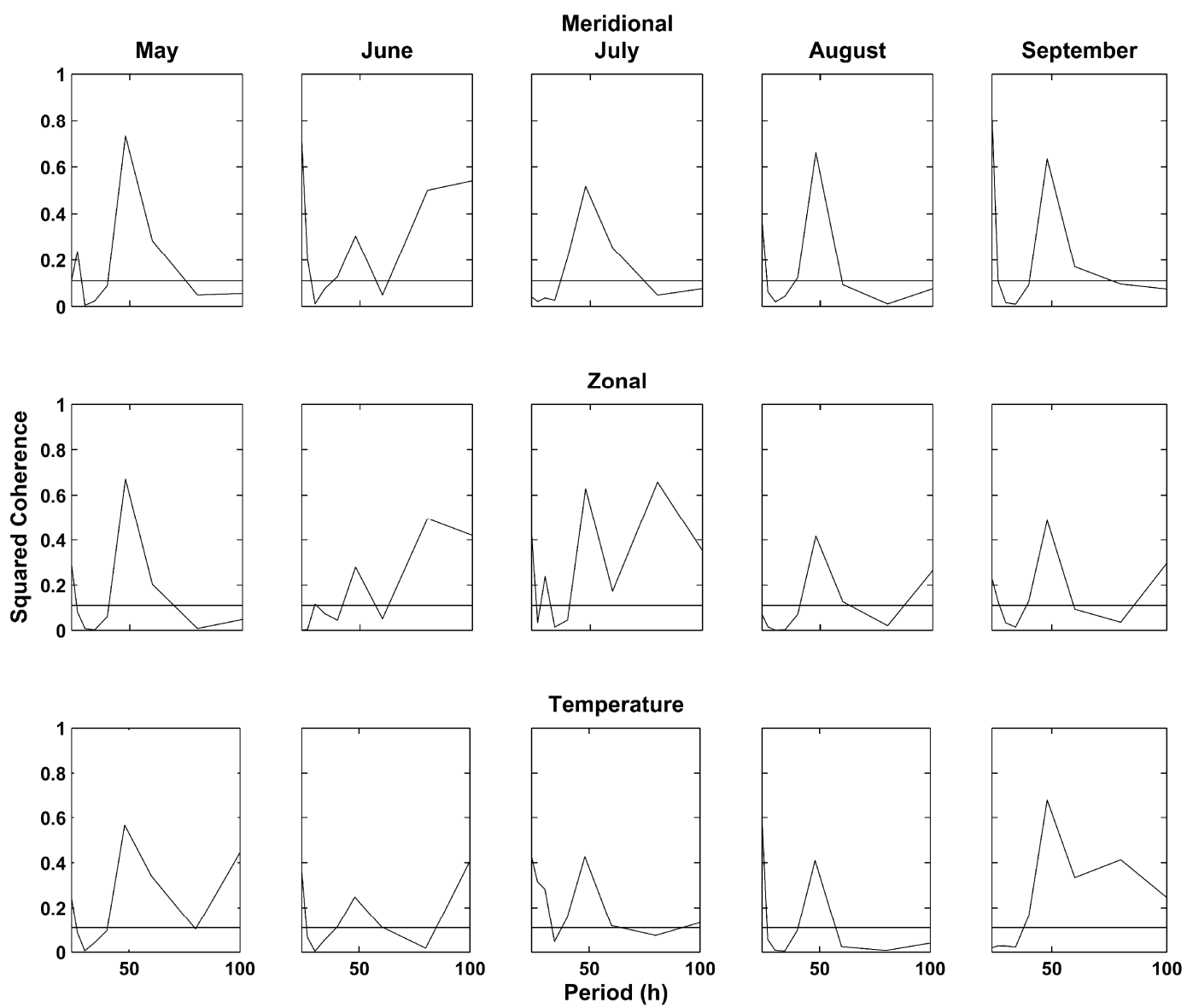

Fig. 8. Squared-coherence between meridional (a), zonal (b) winds and temperature (c) of IMD and ERA datasets for each month. The period range is from $24 \mathrm{~h}$ to $100 \mathrm{~h} .95 \%$ confidence levels have been marked with horizontal solid lines.

mean FFT spectra (Sect. 3.1.1) but for the altitudes between 10 and $25 \mathrm{~km}$ where 2-day oscillations were prominent and both IMD and ERA data were available. Spectra computed for 10 heights in this altitude range were averaged which improved the spectral reliability. The squared-coherence $\left(\mathrm{coh}^{2}\right)$ was then calculated using cross-spectral amplitudes as:

$\operatorname{coh}^{2}(f)=\frac{\overline{S_{\mathrm{xy}}^{2}(f)}}{\overline{S_{\mathrm{x}}^{2}}(f) \overline{S_{\mathrm{y}}^{2}}(f)}$

where $S_{\mathrm{x}}$ and $S_{\mathrm{y}}$ are the PSD spectra of IMD and ERA datasets respectively. $S_{\mathrm{xy}}$ stands for the cross spectra between the IMD and ERA datasets. The degrees of freedom (df) and $95 \%$ confidence level were computed following Kovalam et al. (1999) and Julian (1975). The results for the meridional wind, zonal wind and temperature are shown in Fig. $8 \mathrm{a}, \mathrm{b}, \mathrm{c}$ for each month. The coherence-squared values are found to be highly significant at 2-day period for all the components.

\section{Conclusions}

The quasi-2-day wave activity has been widely studied at mesospheric heights because of its large amplitudes observed in the region. The present work has made an attempt to study the behavior of these waves, in the lower atmosphere over a low latitude station in Northern Hemisphere during the summer solstice when the activity is supposed to be high. Wind and temperature data collected by India Meteorological Department (IMD) twice a day during May-September 2009 have been used for the present study. Simultaneous data obtained from ECMWF Re-Analysis (ERA - Interim) have also been subjected to similar analyses and compared with the measurements.

Spectral analyses were carried out on winds and temperature data. The 2-day wave could be identified despite the presence of strong longer period planetary waves. Predominant oscillations near $48 \mathrm{~h}$ could be seen in the smaller segments of 10 days in both IMD and ERA data. Moving window spectra were computed and the mean wave amplitudes observed in the upper troposphere and stratosphere are found to be quite appreciable ranging between 
2-3 $\mathrm{m} \mathrm{s}^{-1}$ for both zonal and meridional winds. The temperature amplitude maximum is found to be $1.5 \mathrm{~K}$ in this region. Amplitudes observed in ERA data are slightly smaller than IMD values in the same altitude region.

Wavelet analyses show discrete 2-day wave bursts systematically during the observation period at an interval of 5-8 days. Cross spectral analyses were carried out to verify the significance of 2-day wave activity in the present study. Mean cross-spectra between IMD and ERA datasets are presented in terms of squared-coherence and the values are found to be highly significant at 2-day wave period in all the months. It may also be noted that the inertia gravity wave period over Hyderabad $(\sim 40 \mathrm{~h})$ is close to the period of QTDW. A 10 day modulation of a $40 \mathrm{~h}$ oscillation could also deliver a $48 \mathrm{~h}$ sideband. Future study will concentrate on longer datasets including both the summer and winter solstices and to investigate wave-mean flow and wave-wave interaction.

Acknowledgements. The authors thank the college management for their kind encouragement. One of the authors, Salauddin Mohammad, is thankful for the research fellowship offered by ISRO under CAWSES-II program. The authors gratefully acknowledge the constructive comments of the reviewers which substantially improved the quality of the paper.

Topical Editor P. Drobinski thanks two anonymous referees for their help in evaluating this paper.

\section{References}

Goswami, B. N., Sengupta, D., and Suresh Kumar, G.: Intraseasonal oscillations and interannual variability of surface winds over the Indian monsoon region, Proc. Indian Acad. Sci. (Earth Planet. Sci.), 107, 45-64, 1998.

Hamilton, K. and Garcia, R.: Theory and observation of short period normal mode oscillations in the atmosphere, J. Geophys. Res., 91, 11867-11875, 1986.

Jacobi, Ch., Schminder, R., and Kürschner, D.: The quasi-2-day wave as seen from D1 LF wind measurements over central Europe $\left(52^{\circ} \mathrm{N}, 15^{\circ} \mathrm{E}\right)$ at Collm, J. Atmos. Terr. Phys., 59, 12771286, 1997.

Julian, P. R.: Comments on the determination of significance levels of the coherence statistic, J. Atmos. Sci., 32, 836-837, 1975.

Kovalam, S., Vincent, R. A., Reid, I. A., Tsuda, T., Nakamura, T., Ohnish, K., Nuryanto, A., and Wiryosumarto, H.: Longitudinal variations in planetary wave activity in the equatorial mesosphere, Earth Planets Space., 51, 665-674, 1999.

Krishnamurti, T. N. and Bhalme, H. N.: Oscillations of a monsoon system; Part I: Observational aspects, J. Atmos. Sci., 33, 19371954, 1976.

Kulikov, M. Y.: Theoretical investigation of the influence of a quasi-2-day wave on nonlinear photochemical oscillations in the mesopause region, J. Geophys. Res., 112, D02305, doi:10.1029/2005JD006845, 2007.

Lieberman, R. S.: Eliassen-Palm fluxes of the 2-day wave, J. Atmos. Sci., 56, 2846-2861, 1999.
Limpasuvan, V. and Wu, D. L.: Anomalous two-day wave behavior during the 2006 austral summer, Geophys. Res. Lett., 36, L04807, doi:10.1029/2008GL036387, 2009.

Mayr, H. G., Mengel, J. G., Chan, K. L., and Porter, H. S.: Mesosphere dynamics with gravity wave forcing: Part II. Planetary waves, J. Atmos. Solar-Terr. Phys., 63, 1865-1881, 2001.

McCormack, J. P., Eckermann, S. D., Hoppel, K. W., and Vincent, R. A.: Amplification of the quasi-two day wave through nonlinear interaction with the migrating diurnal tide, Geophys. Res. Lett., 37, L16810, doi:10.1029/2010GL043906, 2010.

Meek, C. E., Manson, A. H., Franke, S. J., Singer, W., Hoffmann, P., Clark, R. R., Tsuda, T., Nakamura, T., Tsutsumi, M., Hagan, M., Fritts, D. C., Isler, J., and Portnyagin, Yu. I.: Global study of northern hemisphere quasi-2-day wave events in recent summers near $90 \mathrm{~km}$ altitude, J. Atmos. Terr. Phys., 58, 1401-1411, 1996.

Merzlyakov, E. G. and Jacobi, Ch.: Quasi-two-day wave in an unstable summer atmosphere - some numerical results on excitation and propagation, Ann. Geophys., 22, 1917-1929, doi:10.5194/angeo-22-1917-2004, 2004.

Ngara, T. and Asnani, G. C.: Five-day oscillation in East African Low Level Jet, Nature, 272, 708-709, 1978.

Norton, W. A. and Thuburn, J.: The two day wave in a middle atmosphere GCM, Geophys. Res. Lett., 23, 2113-2116, 1996.

Orlanski, I.: The trapeze instability in an equatorial $\beta$-plane, J. Atmos. Sci., 33, 745-763, 1976.

Palo, S. E., Forbes, J. M., Zhang, X., Russell III, J. M., and Mlynczak, M. G.: An eastward propagating two-day wave: Evidence for nonlinear planetary wave and tidal coupling in the mesosphere and lower thermosphere, Geophys. Res. Lett., 34, L07807, doi:10.1029/2006GL027728, 2007.

Pancheva, D., Mitchell, N. J., and Younger, P. T.: Meteor radar observations of atmospheric waves in the equatorial mesosphere/lower thermosphere over Ascension Island, Ann. Geophys., 22, 387-404, doi:10.5194/angeo-22-387-2004, 2004.

Press, W. H., Teukolsky, S. A., Vetterling, W. T., and Flannery, B. P.: Numerical Recipes in C: The art of scientific computing, 2nd Ed., 994 pp., Cambridge University Press, Cambridge, 1992.

Randel, W. J.: Observations of the two day wave in NMC stratospheric analysis, J. Atmos. Sci., 51, 306-313, 1994.

Salby, M. L.: The two day wave in the middle atmosphere: Observations and theory, J. Geophys. Res., 86, 9654-9660, 1981.

Salby, M. L. and Callaghan, P. F.: Seasonal amplification of the two day wave: Relationship between normal mode and instability, J. Atmos. Sci., 58, 1858-1869, 2001.

Vincent, R. A.: Planetary and gravity waves in the mesosphere and lower thermosphere, Adv. Space Res., 10, 93-101, 1990.

Wu, D. L., Hays, P. B., Skinner, W. R., Marshall, A. R., Burrage, M. D., Lieberman, R. S., and Ortland, D. A.: Observations of the quasi 2-day wave from the high resolution doppler imager on UARS, Geophys. Res. Lett., 20, 2853-2856, 1993.

Wu, D. L., Fishbein, E. F., Read, W. G., and Waters, J. W.: Excitation and Evolution of the quasi-2-day wave observed in UARS/MLS Temperature measurements, J. Atmos. Sci., 53, 728-738, 1996.

Wu, D. L., Schwartz, M. J., Waters, J. W., Limpasuvan, V., Wu, Q., and Killeen, T. L.: Mesospheric Doppler wind measurements from Aura Microwave Limb Sounder (MLS), Adv. Space Res., 42, 1246-1252, doi:10.1016/j.asr.2007.06.014, 2008. 